\title{
Molecular Dynamics Simulation of High Strain-Rate Void Nucleation and Growth in Copper
}

\author{
James Belak \\ This paper was prepared for submittal to the \\ American Physical Society Meeting \\ Amherst, $M A$ \\ July 27-August 1, 1997
}

July 1997

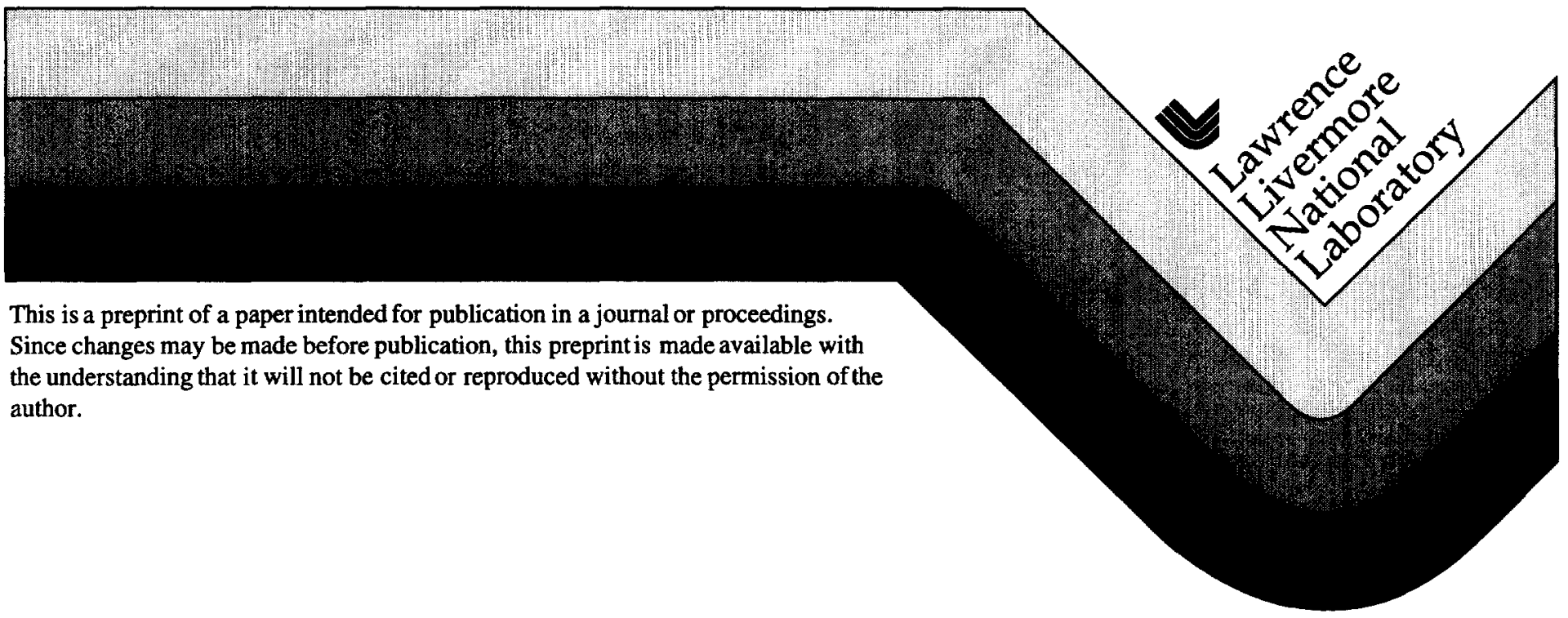




\section{DISCLAIMER}

This document was prepared as an account of work sponsored by an agency of the United States Government. Neither the United States Government nor the University of California nor any of their employees, makes any warranty, express or implied, or assumes any legal liability or responsibility for the accuracy, completeness, or usefulness of any information, apparatus, product, or process

disclosed, or represents that its use would not infringe privately owned rights. Reference herein to any specific commercial product, process, or service by trade name, trademark, manufacturer, or otherwise, does not necessarily constitute or imply its endorsement, recommendation, or favoring by the United States Government or the University of California. The views and opinions of authors expressed herein do not necessarily state or reflect those of the United States Government or the University of California, and shall not be used for advertising or product endorsement purposes. 


\title{
Molecular Dynamics Simulation of High Strain-Rate Void Nucleation and Growth in Copper
}

\author{
James Belak \\ University of California, Lawrence Livermore National Laboratory, Livermore, CA 94550
}

Isotropic tension is simulated in nanoscale polycrystalline copper with 10nm grain size using largescale molecular dynamics. The nanocrystalline copper is fabricated on the computer by growing randomly oriented grains from seed sites in the simulations cell. Constant volume strain rates of $10^{8}-10^{10}$ are considered for systems ranging from $10^{5}-10^{6}$ atoms using an EAM interatomic potential for copper. The spacing between voids for room temperature single crystal simulations is found to scale approximately as $l \sim 0.005 C_{s} / \gamma$, where $C_{s}$ is the sound speed and $\gamma$ is the strain rate.

Below strain rates of about $10^{9}$, only one void is observed to nucleate and grow in the $10 \mathrm{~nm}$ polycrystalline simulation cell. The growth of small voids is simulated by cutting a void out of the simulation cell and repeating the isotropic expansion.

\section{INTRODUCTION}

When tensile shock waves overlap in a ductile metal, extreme states of tension are created and internal failure occurs through the nucleation, growth, and linking of microscopic voids. This process, known as spallation, has been the subject of extensive metallurgical investigation [1-3]. The spallation of ductile metals depends upon the magnitude of the tensile stress, the length of time at stress, and the metallurgical state of the metal (grain size, impurity concentration,...). Experimental measurements of the spall strength of copper range from 1.5 to $4.5 \mathrm{GPa}$ depending on the metallurgical state [4]. Models of spallation are necessarily statistical and continuum in nature. While mature models for void growth are available [5], there remains several issues regarding the growth of small voids in single crystals, the nature of the nucleation process (homogeneous/heterogeneous) and nucleation sites, and the process of void linking at late times. The purpose of the molecular dynamics study presented in this paper is to examine nucleation and early growth in ductile metals under constant strain rate tensile expansion.

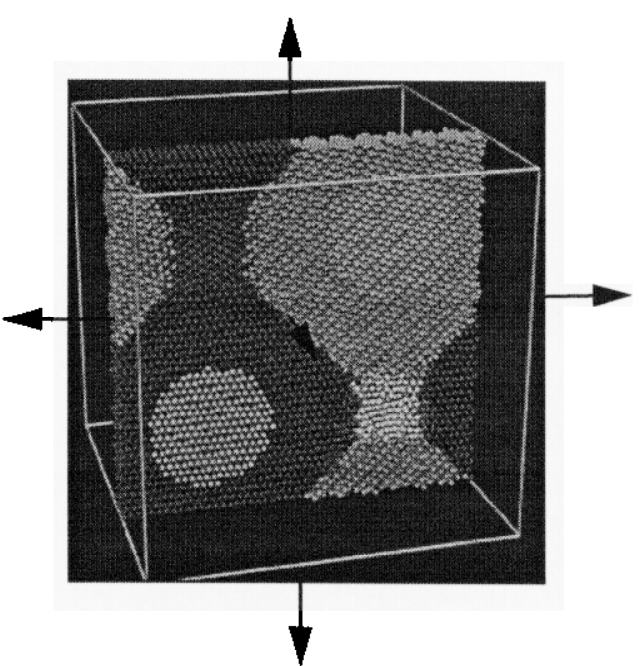

FIGURE 1. A slice through the idealized four grain microstructure used in the void nucleation simulations. The sphere of atoms at the grain center are held fixed during processing and allowed to evolve during failure. The simulation cell is expanded in all directions at a constant rate. 


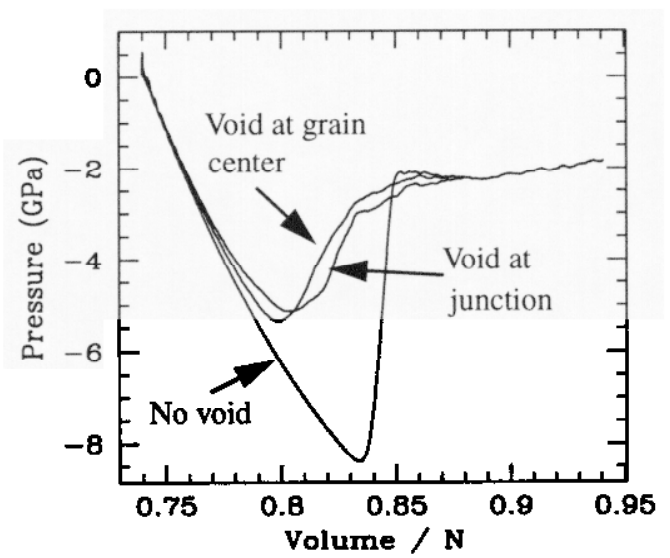

FIGURE 2. Stress as a function of volume per atom $\left(r_{e}^{3}, r_{e}=2.54\right.$ Angs) for a strain rate of $7.7 \times 10^{8} \mathrm{~s}^{-1}$.

\section{METHODS}

A polycrystalline copper metal with nanoscale grains is simulated using the idealized space filling model of Phillpot and coworkers [6]. A thin slice through the simulation cell is shown in Figure 1. On each of four FCC seed sites, within the cubic simulation cell, a randomly oriented grain is grown with the $P=0, T=300 \mathrm{~K}$ lattice spacing out to the Voronoi boundary with the neighboring seed sites while maintaining periodic boundary conditions. The center of each grain is held fixed while the surrounding atoms are brought to the melting temperature at $\mathrm{P}=0$, then returned to $\mathrm{T}=300 \mathrm{~K}$. Using a $12 \mathrm{~nm}$ simulation cell, this procedure generated a four grain microstructure with $\mathrm{N}=141705$ atoms. Each grain has octahedral symmetry.

The embedded-atom method [7] with parameters due to Oh and Johnson [8] is used to model copper. The equations of motion are integrated using a Verlet leap-frog algorithm [9] with a time step of $5 \mathrm{fs}$. Considering the thermal conduction being largely electronic and the mean free path of the electrons being much larger than our simulation cell, we approximate the system at constant temperature $(T=300)$ with a global thermostat [10]. To simulate a constant uniform expansion strain rate, the position of every atom in the simulation cell is written:

$$
\underset{\sim}{x}=H s
$$

where $s \subset[0,1]$ and $H=\{\underset{\sim}{a} \underset{\sim}{b}, \underset{\sim}{c}\}$ is a matrix composed of the three vectors of the simulation cell [11]. A constant strain rate is simulated by specifying a constant time derivative of $H$.

\section{RESULTS AND DISCUSSION}

The resulting stress as a function of volume for a simulated strain rate of $7.7 \times 10^{8} \mathrm{~s}^{-1}$ is shown in Figure 2. The system is elastic up to failure, which occurs at $8.4 \mathrm{GPa}$. Also shown in Figure 2 are the results for simulations at the same strain rate with a

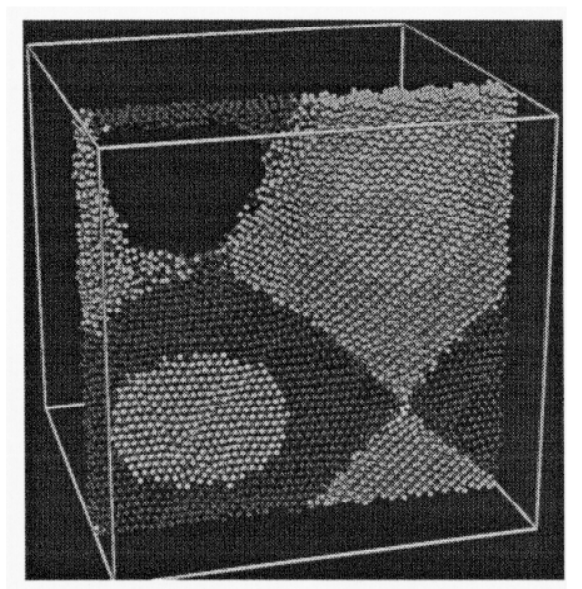

(a)

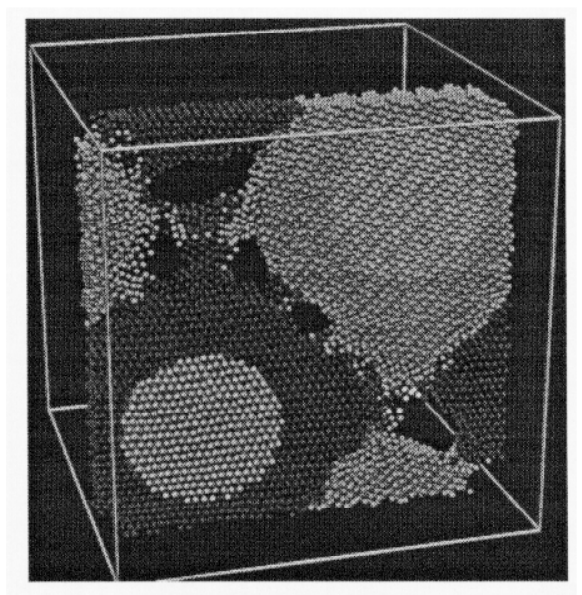

(b)

Figure 3. A slice through the simulation cell at time of failure (a) $\gamma=7.7 \times 10^{8} \mathrm{~s}^{-1}$, (b) $\gamma=6.1 \times 10^{9} \mathrm{~s}^{-1}$. 


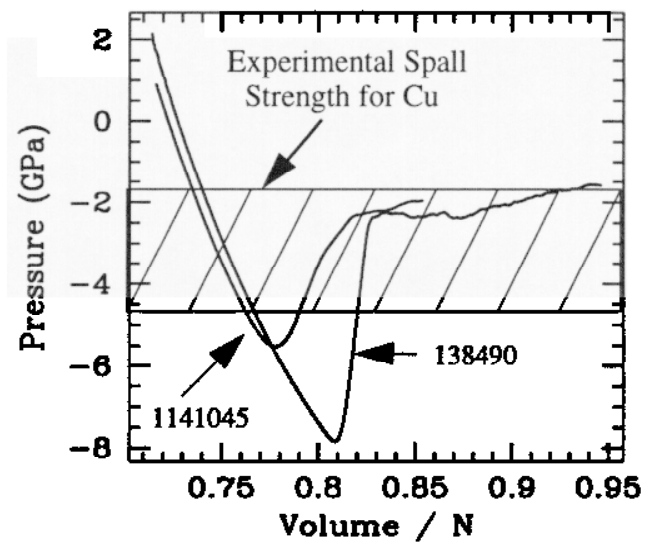

FIGURE 4. Stress curves for two simulations with the same geometric microstructure but differing in the number of atoms per grain. The band is the range of experimental data for copper.

small void $(3.75 \mathrm{~nm})$ placed at the center of one grain and at the junction between all four grains.

A thin slice from the simulation with no preexisting voids is shown at the time of failure in Figure 3a. The system nucleates a single void at the grain junction. This void grows by emitting dislocations into the surrounding grains as can be seen by the mismatch of the lattice planes at the center of the grains and the distortion in grain shape. At a strain rate of $6.1 \times 10^{9} \mathrm{~s}^{-1}$ (Figure 3b), many more voids nucleate and decorate the grain boundaries with very little distortion of the surrounding grains.

The affect of system size was studied by simulating failure in two systems: the first was similar to the previous simulation with different grain orientations and $\mathrm{N}=138490$; the second used the same geometric microstructure and grain orientations, but twice the cell length in each direction. The only difference being the number of atoms, $N=1141045$ in the larger system. The resulting stress curve is shown in Figure 4. The curve for the smaller system is qualitatively the same as before while the larger system yields at a much lower strain. Given the same microstructure and hence the same number of nucleation sites for a slower strain rate, one hypothesis is that the stored elastic energy per nucleation site determines the strain at which failure occurs. This energy is greater for a given strain for the larger system and is the energy available to drive the growth of voids.

Figure 2 illustrates the dependence of the number of voids nucleated at failure upon the strain rate. To investigate this further, we consider the failure of a single crystal so that nucleation is homogeneous. A slice through the simulation cell at the time of failure for a $6.1 \times 10^{9} \mathrm{~s}^{-1}$ strain rate is shown in Figure 5. Several voids are visible. By enumerating the number of voids at this and higher/lower strain rates we quantify the dependence of void spacing on strain rate. The result is shown in Figure 6. Several conclusions are evident. The data in the range of this study is nearly linear on this log-log plot and is well approximated by the expression $l \sim 0.005 C_{s} / \gamma$, where $C_{s}=3480 \mathrm{~m} / \mathrm{s}$ is the bulk sound speed and $\gamma$ is the strain rate. At high strain rates $\left(10^{11} \mathrm{~s}^{-1}\right)$ the void spacing is approaching the interatomic spacing. The study of slower strain rates, in the experimental range, requires much larger system sizes or a special continuum boundary condition.

The simulations presented here are for a fixed strain rate. Experimentally there will be a range of strain rates up to the peak strain rate $\left(\sim 10^{6}\right)$, resulting in a spectrum of void sizes and spacings.

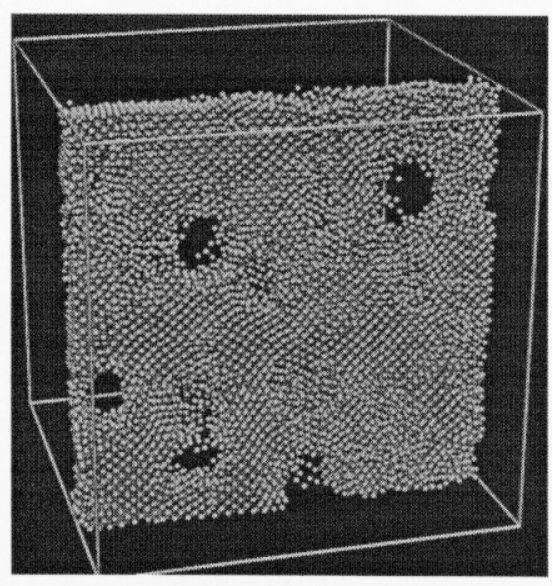

FIGURE 5. A slice through the simulation cell during yielding of single crystal copper at $\gamma=7.7 \times 10^{9} \mathrm{~s}^{-1}$. Several voids are nucleating. 


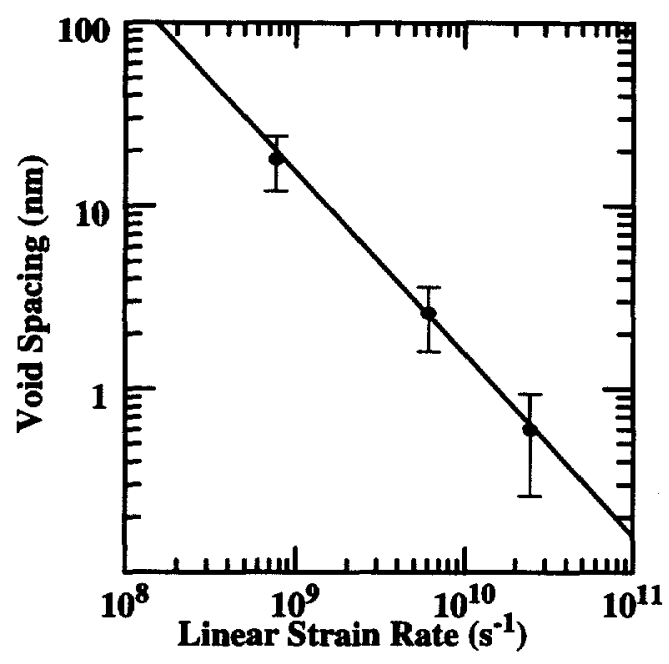

FIGURE 6. The dependence of void spacing on strain rate during simulated isotropic expansion of single crystal copper.

\section{ACKNOWLEDGEMENT}

Work performed under the auspices of the U.S. DOE by LLNL under contract No. W-7405-ENG48.

\section{REFERENCES}

1. Barbee, T.W., Jr., L. Seaman, R. Crewdson, and D. Curran, Journal of Materials, 7, 393 (1972).

2. Meyers, M.A. and C.T. Aimone, Progress in Materials Science, 28, 1 (1983).

3. Curran, D.R., L. Seaman, and D.A. Shockey, Physics Reports, 147, 253 (1987).

4. Zurek, A.K. and M.A. Meyers, in High-Pressure Shock Compression of Solids II: Dynamic Fracture and Fragmentation, L. Davison, D.E. Grady and M. Shahinpoor eds. (Springer-Verlag, New York, 1996).

5. Gurson, A.L., J. Eng Materials and Tech., 99, 2 (1977).

6. Phillpot, S.R., J. Wang, D. Wolf, H. Gleiter, Mat Science and Eng., A204, 76 (1995).

7. Daw, M.S., and M.I. Baskes, Phys. Rev B 29, 6443 (1984).

8. Oh, D.J. and R.A. Johnson, in Atomistic Simulation of Materials: Beyond Pair Potentials, V. Vitek and D.J. Srolovitz eds. (Plenum, New York, 1989).

9. Allen, M.P. and D.J. Tildesley, Computer Simulation of Liquids (Clarendon Press, Oxford, 1987).

10. Hoover, W.G., Phys. Rev. A 31, 1695 (1985).

11. Parrinello, M. and A. Rahman, J. Appl. Phys. 52, 7182 (1981). 


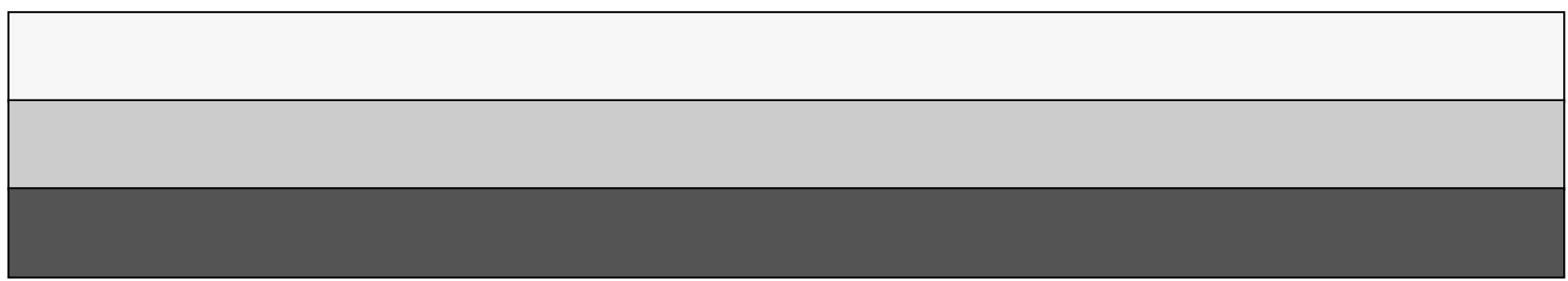

